\title{
ANALYSIS OF TEMPERATURE FIELD IN A COMPOSITE FUNCTIONALLY GRADED MATERIAL PLATE BY FINITE ELEMENT METHOD
}

\author{
Rajesh Sharma ${ }^{1}$,Vijay Kumar Jadon ${ }^{2}$ and Balkar Singh ${ }^{3}$ \\ ${ }^{1}$ Research Scholar, P.T.U, Jalandhar \\ ${ }^{2}$ Dean engineerig, B.U.E.S.T , Baddi(Solan),H.P. \\ ${ }^{3}$ Director, College Development, P.T.U, Jalandhar
}

\begin{abstract}
A finite element model is constructed to analyze the effects of steady state temperature field on FGM layer thickness. The first-order shear deformation model is exploited to investigate the uncoupled thermal behavior of functionally graded plates in Abacus environment. The continuum is divided into 540 elements and 541 nodes using two node linear elements. The results show that the temperature distribution in the composite plate is more reasonable with increase in the thickness of FGM layer. The comparison with the non-graded two layered composite plate, the temperature field of the Zirconia/FGM/Aluminum three layered composite plate is in the form of a curve but in case of non-graded two layered composite plate the temperature field is in the form of inclined straight line with sharp bend at the interface of metal and ceramic phase.
\end{abstract}

\section{Keywords}

Finite element, functionally graded material (FGM), temperature field.

\section{INTRODUCTION}

Functionally graded materials (FGM) are microscopically inhomogeneous composite materials, in which the volume fraction of the two or more materials is varied smoothly and continuously as a continuous function of the material position along one or more dimension of the structure. These materials are mainly constructed to operate in high temperature environments. FGM were developed to reduce such thermal stress and resist super high temperature. To reduce stress and resist super high temperature, FGM have continuous transition from metal at low temperature surfaces to ceramics at high temperature surfaces because it is used widely in high temperature working environment such as aviation and nuclear reactor and so on, it is important to analyze the temperature and thermal stress field of the body made of the materials [1]. Yangjian et. al. [2] researched the effect of FGM layer thickness on temperature field by finite element method. In their research they constructed a finite element model to analyze the steady temperature field in a ceramic/metal composite FGM plate under heating boundary. The FGM is suitable for various 
applications like rocket engine components, armour plates, dental and orthopedic uses optical thin layers, and biomaterial electronics. A comprehensive review of design, processing, and modeling as well as applications of FGMs can be found in books by [3] Suresh and Mortensen, and by [4] Miyamoto et al. R. Ramkumar and N. Ganesan [5] studied the problem of buckling behaviors of thin walled box columns in a thermal environment by using CLPT theory; they use this theory with different software packages. Chen and Tong [6] used a graded finite element approach to analyze the sensitivity in the problems of steady state and transient heat conduction in FGM. Therefore, FGMs have received considerable attention in the field of structural design subjected to extremely high thermal loading [7-8]. Because it is used widely in high temperature working environment such as aviation and nuclear reactor, and so on, it is important to analyze the thermal stress filed of the body made of the material. Obata [9] and Tanigawa [10] researched thermal stress of pure FGM plate by adopting perturbation and laminated analytical method, respectively. Huang [9] analyzed the thermal elastic limitation of four-layered composite plate with FGM in the middle of the plate. But these methods are too complex so as to lead to a complicated equation system, and are not convenient for engineering application. Thermal stress analysis of FGM plates is done by Rajesh et. al. [11]. Various analytical methods have been presented for the analysis of functionally graded material [12-18]. The above research work, starting from the heat conduction law, will discuss the effects of steady state temperature field on FGM layer thickness and composition by using finite element method.

\section{DEVELOPMENT OF MODEL}

Three layered infinite long composite plate made of pure Aluminum and pure ceramic (Zirconia) with an interlayer of FGM is considered for analysis as shown in Figure 1.The middle layer is continuous and varying in volume fraction. $\mathrm{k}(\mathrm{z}), \mathrm{E}(\mathrm{z})$ and $\alpha(\mathrm{z})$ denote thermal conductivity, modulus of elasticity and coefficient of thermal expansion respectively of FGM gradient layer and the layer thickness is $t_{2}=t_{\mathrm{FGM}}$. The top layer is of pure ceramic i.e. have properties $\mathrm{k}_{\mathrm{c}}, \mathrm{E}_{\mathrm{c}}, \alpha_{\mathrm{c}}$ similarly for metal the values are $\mathrm{k}_{\mathrm{m}}, \mathrm{E}_{\mathrm{m}}, \alpha_{\mathrm{m}}$. The thickness of ceramic layer is $\mathrm{t}_{1}$ and that of metal layer is $\mathrm{t}_{3}$.

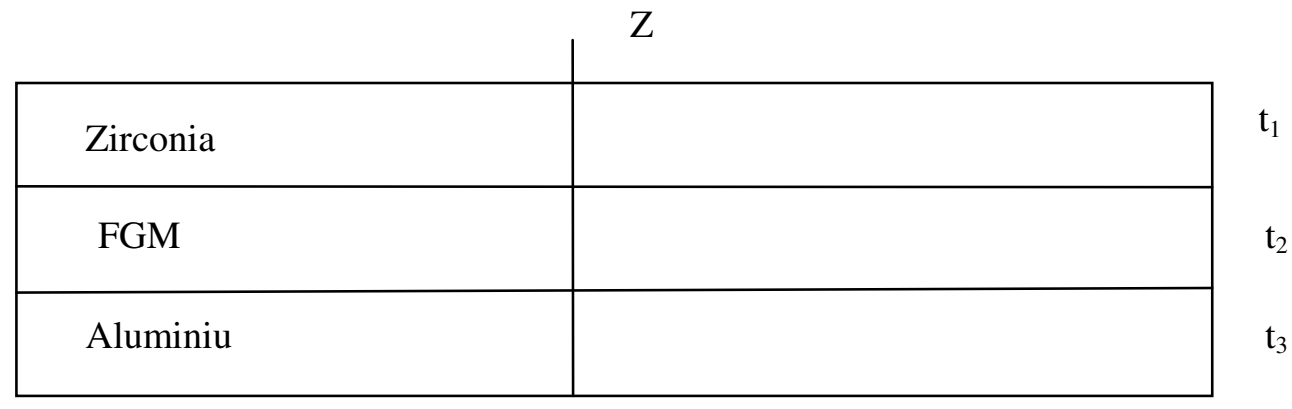

Figure 1. Zirconia/FGM/ Aluminum composite FGM plate.

Three layered infinite long composite plate made of pure Aluminum and pure ceramic (Zirconia) with an interlayer of FGM is considered for analysis. The middle layer is continuous and varying in volume fraction. $\mathrm{k}(\mathrm{z}), \mathrm{E}(\mathrm{z})$ and $\alpha(\mathrm{z})$ denote thermal conductivity, modulus of elasticity and coefficient of thermal expansion respectively of FGM gradient layer and the layer thickness is $\mathrm{t}_{2}=\mathrm{t}_{\mathrm{FGM}}$. The top layer is of pure ceramic i.e. have properties $\mathrm{k}_{\mathrm{c}}, \mathrm{E}_{\mathrm{c}}, \alpha_{\mathrm{c}}$ similarly properties for 
International Journal of Advances in Materials Science and Engineering (IJAMSE) Vol.4, No.4, October 2015

bottom layer made of metal are $\mathrm{k}_{\mathrm{m}}, \mathrm{E}_{\mathrm{m}}, \alpha_{\mathrm{m}}$. The thickness of ceramic layer is $\mathrm{t}_{1}$ and that of metal layer is $t_{3}$.

\section{HEAT CONDUCTION EQUATIONS}

The one dimensional heat conduction equation for composite plate is:

$\frac{d}{d z}\left\{k(\mathrm{z}) \frac{d \mathrm{~T}}{d z}\right\}=0$

Where $\mathrm{k}_{\mathrm{i}}(\mathrm{z})$ is the thermal conductivity of per layer of the three layered composite plate such as $\mathrm{i}=1, \mathrm{k}_{1}(\mathrm{z})=\mathrm{k}_{\mathrm{c}}$ and $\mathrm{k}_{3}(\mathrm{z})=\mathrm{k}_{\mathrm{m}}$.

Thermal conductivity for FGM layers is $\mathrm{k}(\mathrm{z})$.

\section{FINITE ELEMENT ANALYSIS}

Consider one dimensional element as shown in the Figure 2 with nodes i \& j, we can write

$T=N_{i} T_{i}+N_{j} T_{j}$

Figure 2. Linear element with nodes $\mathrm{i}$ and $\mathrm{j}$.

where

$N_{i}=\frac{y_{j}-y}{y_{j}-y_{i}} \& N_{j}=\frac{y-y_{i}}{y_{j}-y_{i}}$

In local co-ordinates

$N_{i}=1-y / l \& N_{j}=y / l$

and temperature is $\mathrm{dT} / \mathrm{dy}=-\frac{1}{l} T_{i}+\frac{1}{l} T_{j}$

$=\left[\begin{array}{cc}-\frac{1}{l} & \frac{1}{l}\end{array}\right]\left\{\begin{array}{l}T_{i} \\ T_{j}\end{array}\right\}=[B][T]$ where $\mathrm{l}_{\mathrm{e}}$ is the length of element. The element stiffness matrix is given as [18]

$$
\begin{aligned}
{[K]_{e} } & =\int_{\Omega}[B]^{T}[D][\mathrm{B}] \mathrm{d} \Omega+\int_{A} h[N]^{T}[N] d A_{s} \\
& =\int_{\Omega}[B]^{T}[D][\mathrm{B}] \mathrm{Ad} x+\int_{A} h[N]^{T}[N] d A_{s}
\end{aligned}
$$

Where $\Omega$ is the volume integral, $\mathrm{A}_{\mathrm{s}}$ indicates surface area and $\mathrm{h}$ is the convective heat transfer coefficient after integration

$[K]_{e}=\frac{A k}{l}\left[\begin{array}{cc}1 & -1 \\ -1 & 1\end{array}\right]+h A_{s}\left[\begin{array}{ll}0 & 0 \\ 0 & 1\end{array}\right]$ 
The forcing vector can be written as

$$
\{f\}_{e}=\int_{\Omega} G[N]^{T} d \Omega-\int_{A_{s}} q[N]^{T} d A_{s}+\int_{A_{s}} h\left[T_{a}\right][N]^{T} d A_{s}
$$

Where $\mathrm{G}$ is the internal heat generation per unit volume, $\mathrm{q}$ is the boundary surface heat flux and $\mathrm{T}_{\mathrm{a}}$ is the atmospheric temperature. In our case $\mathrm{G}=0$. The no heat flux boundary condition is denoted by $\mathrm{q}=0$, so finite element equation for a each layer of FGM composite plate with two nodes becomes

$$
[K]_{e}=\frac{A k}{l}\left[\begin{array}{cc}
1 & -1 \\
-1 & 1
\end{array}\right]+h A_{s}\left[\begin{array}{ll}
0 & 0 \\
0 & 1
\end{array}\right]\left\{\begin{array}{l}
T_{1} \\
T_{2}
\end{array}\right\}=\left\{\begin{array}{c}
0 \\
h T_{a} A
\end{array}\right\}
$$

\section{RESULT AND DISCUSSIONS}

The total thickness of plate is $10 \mathrm{~mm}$ and $\mathrm{t}_{1}=\mathrm{t}_{3}$. Abaqus subroutine USDFLD has been used for the simulation of plate. The finite element mesh of Zirconia/FGM/Al composite plate is divided into 540 elements and 541 nodes. The nodes are at the interfaces of three layered plate.

\subsection{Variation of temperature field with FGM layer.}

Figure 3 shows the variation of temperature field due to the FGM layer thickness. So it can be observed in the figure that the temperature in the composite FGM plate changes from smaller temperature in metal layer to the larger temperature in the ceramic layer. In metal and ceramic layers the change in temperature is linear but in FGM layer temperature distribution is curvilinear and with increase in the thickness the temperature curves tend to gentle and temperature distribution in composite FGM becomes smooth.

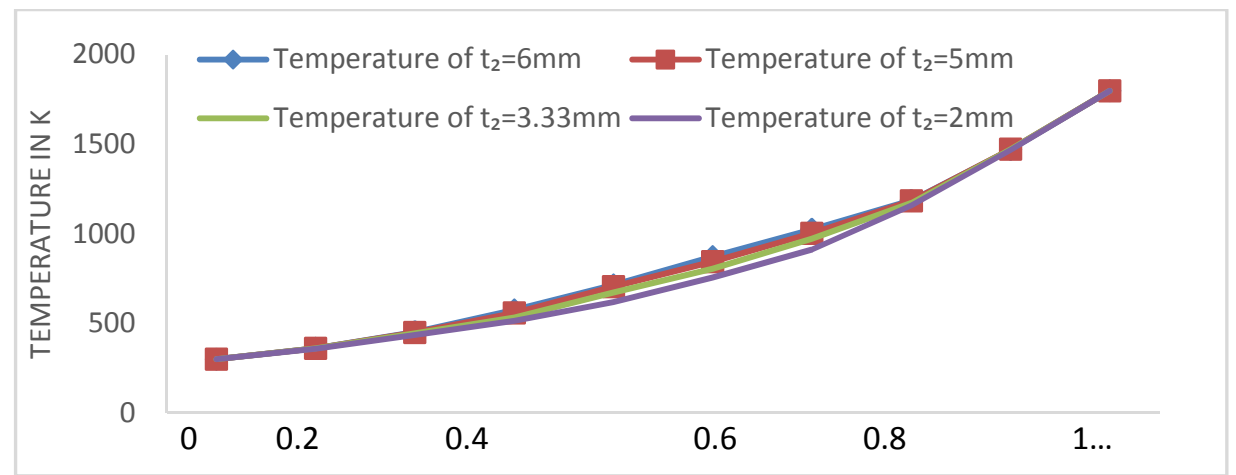

Figure 3. Variation of temperature field with FGM layer.

\subsection{Variation of temperature field with composition of FGM layer.}

We can know from Figure 4 that in metal and ceramic layers, the temperature distribution is almost incline straight lines and with the increase of gradient parameter $\mathrm{n}$, the temperature curve increases gradually and the value of temperature of each curve is different. But in FGM layer, the temperature distribution is smooth and with increase of FGM layer the gradient of temperature curve decreases gradually. When $n=0.1$, the temperature curve appears turning point and when 
International Journal of Advances in Materials Science and Engineering (IJAMSE) Vol.4, No.4, October 2015

$\mathrm{n}=10$ the temperature curve appears turning point at the interface of FGM layer and ceramic layer, but when $n=1$ the temperature curve is a slightly bending curve with gentle smoothness.

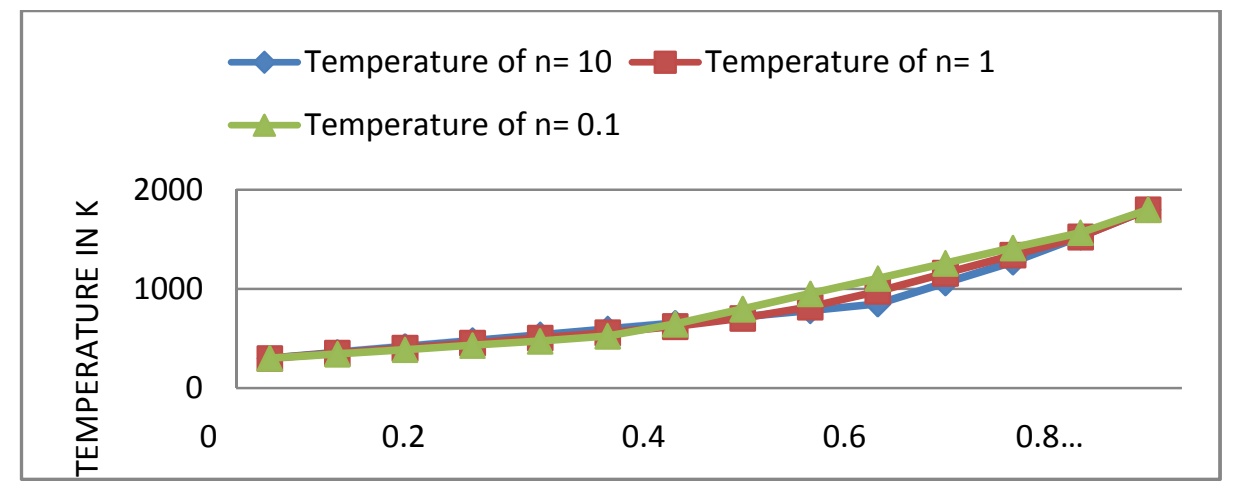

Figure 4. Variation of temperature field with composition of FGM layer.

\subsection{Variation of temperature field with different composite plate.}

Figure 5 shows the effect of the different composite plate on temperature field. In the metal layer, the variation of temperature of two composite plates is similar, and are almost incline straight lines, but their gradients are different, the gradient of the temperature curve in the non graded two-layered composite plate is larger than that in the temperature of the ceramic/metal composite FGM plate.

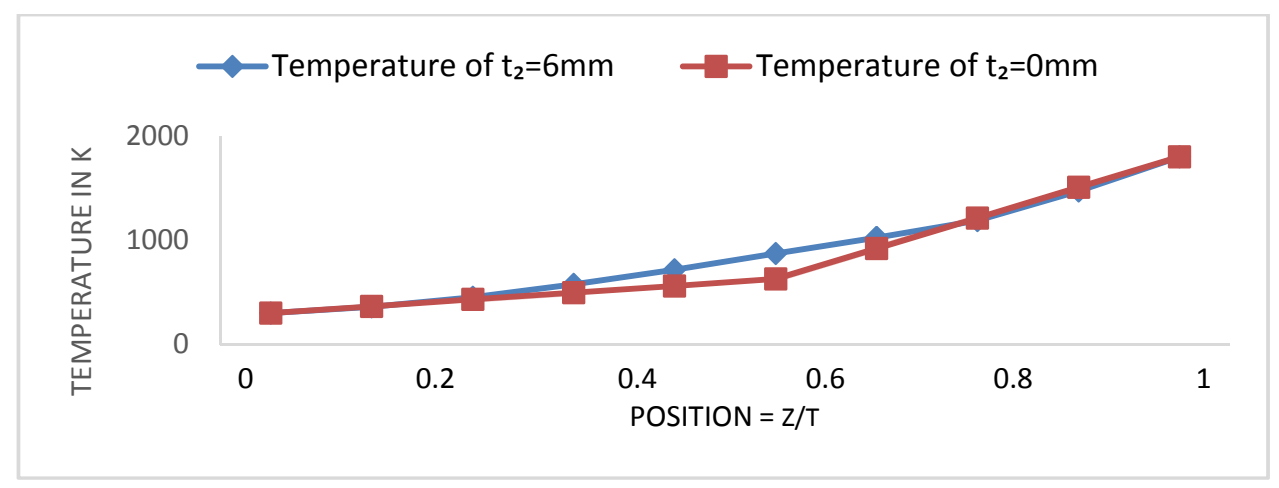

Figure 5. Variation of temperature field with different composite plate.

\subsection{Variation of temperature field with different heating temperature.}

Figure 6 and 7 show the effect of the different heating temperature on temperature field. Figure 6 shows the variations of temperature curves when $T_{L}=300 \mathrm{~K}, 500 \mathrm{~K}, 700 \mathrm{~K}, 900 \mathrm{~K}$ and $\mathrm{T}_{\mathrm{U}}=1800 \mathrm{~K}$. Where $T_{L}$ and $T_{U}$ are temperatures at lower and upper surfaces of FGM plate,with the increase of $\mathrm{T}_{\mathrm{L}}$, the variations of temperature curves become small, and the temperature curve 4 is more gentle and smooth than curve 1, and also the slope of the curve 4 is smaller than that of curve 1 obviously, compared with the curve 1 , in the curve 4 , the temperature on the surface of metal increases by $200 \%$. Figure 7 shows the variations of temperature curves when $T_{L}=300 \mathrm{~K}$ and 
International Journal of Advances in Materials Science and Engineering (IJAMSE) Vol.4, No.4, October 2015

$\mathrm{T}_{\mathrm{U}}=1050 \mathrm{~K}, 1300 \mathrm{~K}, 1550 \mathrm{~K}, 1800 \mathrm{~K}$. With the increase of $\mathrm{T}_{\mathrm{U}}$, the variations of temperature curves become big, and the temperature curve 1 is more gentle and smooth than curve 4 . And also the slope of the curve 1 is smaller than that of curve 4 obviously. As compared with the curve 1, in the curve 4 , the temperature on the surface of ceramics increases by $72 \%$.

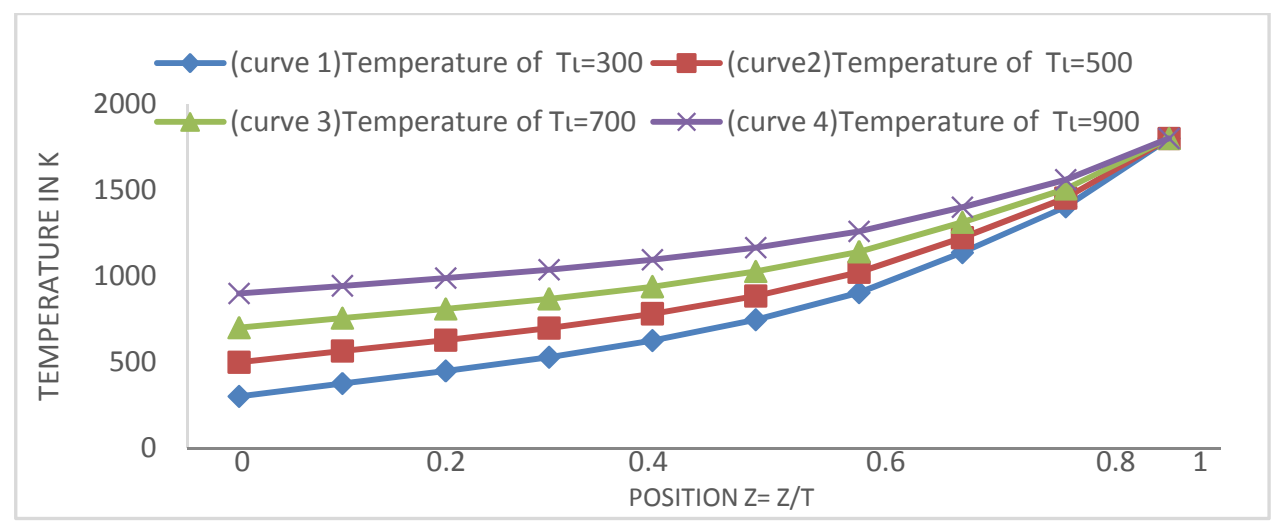

Figure 6. Variation of temperature field with different heating temperature (with $T_{U}$ fixed $T_{L}$ is varying)

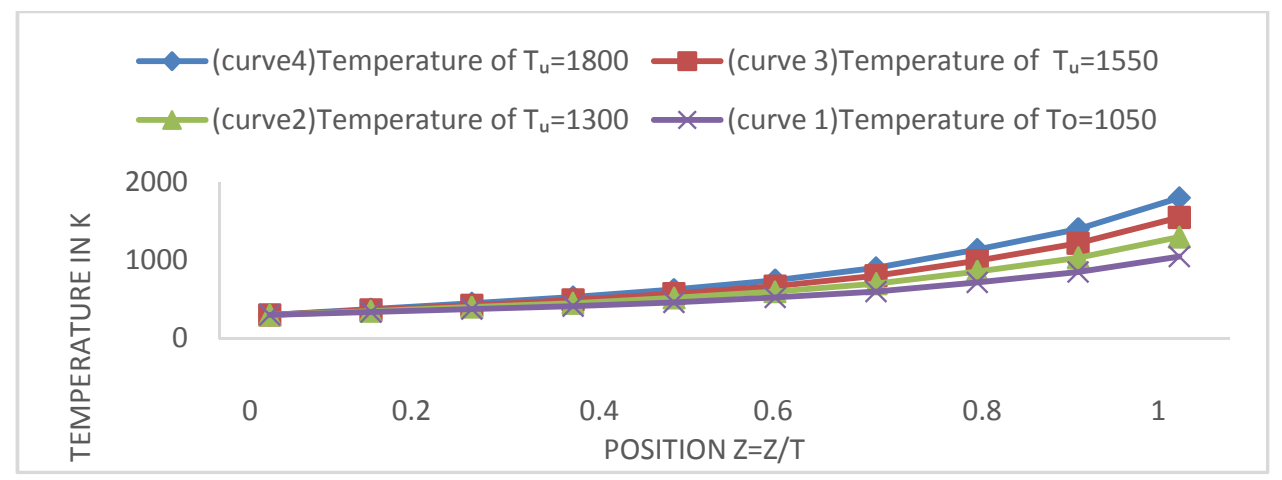

Figure 6. Variation of temperature field with different heating temperature (with $T_{L}$ fixed $T_{U}$ is varying)

\section{CONCLUSION}

Three layered composite FGM plate is analyzed with thermal boundary condition as heating boundary .The one dimensional heat conduction of composite FGM plate is derived using the finite element basic equation. Abacus software is used and simulations are done on the composite plate to obtain numerical results which led to the following conclusions:

(1)The variation of FGM layer thickness has significant effect on temperature field, with increase in thickness of FGM layer the temperature field shows smooth and gentle behavior which is reasonable with comparison to two layered composite, in which the behavior of temperature field is sharp inclined lines.

(2) The variation of FGM layer composition shows that with increase in grading parameter $\mathrm{n}$, the gradient of temperature curve increases gradually. 
International Journal of Advances in Materials Science and Engineering (IJAMSE) Vol.4, No.4, October 2015

(3) The variation of different heating temperature on temperature field of FGM composite plate concludes that as the heating temperatures are increased, the temperature variations are smooth and very reasonable in the plate.

\section{REFERENCES}

[1] Rajesh Sharma, V.K. Jadon and B. Singh (2015) "A review of the finite element based methods for thermal analysis of functionally graded materials", Journal of The Institution of Engineers (India): Series C(under Springer), Vol.96(1), pp. 73-81.

[2] Yangjian Xu,Ling ling wang and Zhiwei zhang(2000), "Analysis of Convective heat transfer steady thermal stresses in a $\mathrm{Zro}_{2} / \mathrm{FGM} / \mathrm{Ti}-6 \mathrm{Al}-4 \mathrm{~V}$ composite plate by FEM," International Joint conference on computational sciences and optimization.

[3] Suresh, S., and Mortensen, A., 1998, Fundamentals of Functionally Graded Materials, IOM Communications, London.

[4] Miyamoto, Y., Kaysser, W. A., Rabin, B. H., Kawasaki, A., and Ford, R. G., 1999, Functionally Graded Materials: Design, Processing and Applications,Kluwer Academic, Dordrecht.

[5] K Ramkumar and N Ganesan, "Finite-element buckling and vibration analysis of functionally graded box columns in thermal environments", Journal materials: Design and Applications, 222 pp. 53-64.

[6] Chen,B., and Tong, L., (2004), "Sensitivity Analysis of heat Conduction for functonally graded materials," Mater. Des., 25, pp. 663-672.

[7] Y. Tanigawa (1995), "Some basic thermoelastic problems for nonhomogeneous structural materials”, Appl Mech Rev., ASME, New York, 48 pp.287-300.

[8] Y. Li, Z.M. Zhang, S.Y. Ma (2000), "Progress of the study on thermal stress of heat-resisting functionally gradient materials", Advances in Mechanics, CMES, Beijing, 30, pp.571-580.

[9] Y. Obata, N. Noda (1993), "Unsteady thermal stresses in a functionally gradient material plate", Trans. JSME, Series A, JSME, Tokyo, 59, pp.1097-1103.

[10] Y. Tanigawa, T.Akai, R.Kawamura, and N. Oka (1996), "Transient heat conduction and thermal stress problems of a nonhomogeneous plate with temperature-dependent material properties", J. Thermal stresses, Taylor \& Francis Ltd, Philadelphia, 19 ,pp.77-102.

[11] Rajesh Sharma, V.K. Jadon and B. Singh (2014), "Analysis of Thermal Stresses in a Composite Functionally Graded Material Plate by Finite Element Method", International Journal of Engineering and Management Research, Vol 4(5), open access.

[12] J. Huang, Y. B. Lü (2003), "Thermal elastic limit analysis of layered plates of ceramic/metal functionally graded material”, J. Wuhan Univ. Technol. (Trans. Sci. \& Engg.), Wuhan Univ., Wuhan, 17 ,pp.754-757.

[13] Senthil S. Vel, R.C. Batra. Three-dimensional analysis of transient thermal stresses in functionally graded plates. Int J of Solids Struct 2003; 40: 7181-96.

[14] Xu Yangjian, Tu Daihui, Du Haiyang. Convective Heat Transfer Steady Heat Conduction and Thermal Stress in a Ceramic/FGM/Metal Composite EFBF Plate. J Software 2011 ;6:201-08.

[15] Chen Wei-qiu, Bian Zu-guang ,Ding hao-jiang.Three-dimensional analysis of a thick FGM rectangular plate in thermal environment. J Zhejiang Univ Sci.2011;4:1-7.

[16] Fumihiro Ashida, Takuya Morimoto, Tatsuya Ohtsuka. Dynamic behavior of thermal stress in a functionally graded material thin film subjected to thermal shock. J Therm Stresses 2014; 37:103751.

[17] Yoshihiro Ootao. Transient thermoelastic and piezothermoelastic problems of functionally graded materials. J Therm Stresses 2009; 32:656-97.

[18] L. F. Qian , R. C. Batra. Three-Dimensional transient heat conduction in a functionally graded thick plate with a higher-order plate theory and a meshless local Petrov-Galerkin method. Comput Mech 2005;35: 214 -26 